\title{
Daily Weather and Children's Physical Activity Patterns
}

Citation for published version (APA):

Remmers, T., Thijs, C., Timperio, A., Salmon, J., Veitch, J., Kremers, S. P. J., \& Ridgers, N. D. (2017). Daily Weather and Children's Physical Activity Patterns. Medicine and Science in Sports and Exercise, 49(5), 922-929. https://doi.org/10.1249/MSS.0000000000001181

Document status and date:

Published: 01/05/2017

DOI:

10.1249/MSS.0000000000001181

Document Version:

Publisher's PDF, also known as Version of record

Document license:

Taverne

Please check the document version of this publication:

- A submitted manuscript is the version of the article upon submission and before peer-review. There can be important differences between the submitted version and the official published version of record.

People interested in the research are advised to contact the author for the final version of the publication, or visit the DOI to the publisher's website.

- The final author version and the galley proof are versions of the publication after peer review.

- The final published version features the final layout of the paper including the volume, issue and page numbers.

Link to publication

\footnotetext{
General rights rights.

- You may freely distribute the URL identifying the publication in the public portal. please follow below link for the End User Agreement:

www.umlib.nl/taverne-license

Take down policy

If you believe that this document breaches copyright please contact us at:

repository@maastrichtuniversity.nl

providing details and we will investigate your claim.
}

Copyright and moral rights for the publications made accessible in the public portal are retained by the authors and/or other copyright owners and it is a condition of accessing publications that users recognise and abide by the legal requirements associated with these

- Users may download and print one copy of any publication from the public portal for the purpose of private study or research.

- You may not further distribute the material or use it for any profit-making activity or commercial gain

If the publication is distributed under the terms of Article $25 \mathrm{fa}$ of the Dutch Copyright Act, indicated by the "Taverne" license above, 


\title{
Daily Weather and Children's Physical Activity Patterns
}

\author{
TEUN REMMERS ${ }^{1}$, CAREL THIJS ${ }^{1}$, ANNA TIMPERIO ${ }^{2}$, JO SALMON ${ }^{2}$, JENNY VEITCH $^{2}$, STEF P. J. KREMERS ${ }^{3}$, \\ and NICOLA D. RIDGERS ${ }^{2}$ \\ ${ }^{1}$ Department of Epidemiology, CAPHRI Care and Public Health Research Institute, Maastricht University (Medical Center+), \\ Maastricht, THE NETHERLANDS; ${ }^{2}$ School of Exercise and Nutrition Sciences, Institute for Physical Activity and Nutrition \\ (IPAN), Deakin University, Geelong, AUSTRALIA; and ${ }^{3}$ Department of Health Promotion, NUTRIM School for Nutrition and \\ Translational Research in Metabolism, Maastricht University (Medical Center+), Maastricht, THE NETHERLANDS
}

\begin{abstract}
REMMERS, T., C. THIJS, A. TIMPERIO, J. SALMON, J. VEITCH, S. P. J. KREMERS, and N. D. RIDGERS. Daily Weather and Children's Physical Activity Patterns. Med. Sci. Sports Exerc., Vol. 49, No. 5, pp. 922-929, 2017. Introduction: Understanding how the weather affects physical activity (PA) may help in the design, analysis, and interpretation of future studies, especially when investigating PA across diverse meteorological settings and with long follow-up periods. The present longitudinal study first aims to examine the influence of daily weather elements on intraindividual PA patterns among primary school children across four seasons, reflecting day-to-day variation within each season. Second, we investigate whether the influence of weather elements differs by day of the week (weekdays vs weekends), gender, age, and body mass index. Method: PA data were collected by ActiGraph accelerometers for 1 wk in each of four school terms that reflect each season in southeast Australia. PA data from 307 children (age range 8.7-12.8 yr) were matched to daily meteorological variables obtained from the Australian Government's Bureau of Meteorology (maximum temperature, relative humidity, solar radiation, day length, and rainfall). Daily PA patterns and their association with weather elements were analyzed using multilevel linear mixed models. Results: Temperature was the strongest predictor of moderate and vigorous PA, followed by solar radiation and humidity. The relation with temperature was curvilinear, showing optimum PA levels at temperatures between $20^{\circ} \mathrm{C}$ and $22^{\circ} \mathrm{C}$. Associations between weather elements on PA did not differ by gender, child's age, or body mass index. Conclusions: This novel study focused on the influence of weather elements on intraindividual PA patterns in children. As weather influences cannot be controlled, knowledge of its effect on individual PA patterns may help in the design of future studies, interpretation of their results, and translation into PA promotion. Key Words: ACCELEROMETER, METEOROLOGY, WEATHER ELEMENTS, INTRAINDIVIDUAL, CHILD, MODERATION
\end{abstract}

he importance of regular physical activity (PA) and the range of associated short- and long-term benefits in children and adolescents are now globally established and accepted $(16,29)$. However, many children in Western countries are insufficiently active (13), with inactivity tending to track from youth to adulthood (17). This makes the promotion of children's PA a critical health promotion target. To develop effective interventions to increase PA, it is important to understand why, when, and how much PA is performed. The development and validation of accelerometers has been an important contribution to this, as accelerometers can provide rich and objective data for extended periods of time (4).

\footnotetext{
Address for correspondence: Teun Remmers, M.Sc., PO Box 616, 6200MD Maastricht, the Netherlands; E-mail: teun.remmers@maastrichtuniversity.nl. Submitted for publication August 2016.

Accepted for publication November 2016.

Supplemental digital content is available for this article. Direct URL citations appear in the printed text and are provided in the HTML and PDF versions of this article on the journal's Web site (www.acsm-msse.org).

0195-9131/17/4905-0922/0

MEDICINE \& SCIENCE IN SPORTS \& EXERCISE E $_{8}$

Copyright $(2017$ by the American College of Sports Medicine

DOI: $10.1249 /$ MSS.0000000000001181
}

An important complicating aspect for studies seeking to identify determinants of children's PA patterns stems from variability in weather conditions. This may be particularly problematic for studies exploring the determinants of PA, which take place outdoors. For example, relationships between aspects of walkability and active transport may be moderated by the weather as children may be more likely to walk to school instead of using motorized transport in favorable weather conditions (22). Lack of consideration of weather conditions may compromise the findings of observational studies and influence intervention outcomes. Hence, understanding how the weather affects PA may help future studies to analyze and interpret PA patterns, especially when measuring across diverse meteorological settings and with long follow-up periods. In addition, studies investigating the influence of the weather may help future interventions to target inactive periods to overcome weather-related PA declines $(9,25)$.

The majority of studies that have examined weather and objectively measured PA behavior in children have focused on seasonality $(5,25)$. Most European studies have generally found that PA is highest in summer and lowest in winter, but results from other continents are inconsistent (25). This inconsistency may be explained by scheduling of organized sports or school curricula $(6,26)$ or regional differences in 
specific weather elements (e.g., rainfall, temperature, wind, relative humidity, etc.) $(11,25)$. International comparisons are limited as average weather conditions within season vary considerably across the world (21). Consequently, although season is a proxy for general differences in weather conditions, seasonal variation does not fully capture the temporal influence of weather on PA behavior. In contrast to seasonal differences, consideration of the influence of actual daily weather elements (e.g., temperature, humidity, solar radiation) does enable international comparisons (21) and provides more detailed information about weather-related differences in children's PA. The investigation of weather elements and their influence on activity levels is therefore warranted $(5,19)$.

To the best of our knowledge, only the studies of Goodman et al. (12), Duncan et al. (9), Harrison et al. (14,15), and Lewis et al. (21) have focused on weather elements by matching daily meteorological data to accelerometer measurements in children. However, in three studies, data were only collected during a single measurement period (i.e., only one season $[9,12,21])$. Single measurement periods may lack variability in weather elements and may not reflect yearly (season-related) variability of weather elements (9). Studies measuring PA within a wide time span using multiple measurement periods across seasons are needed to investigate the full range of these weather elements. In addition, the three studies described previously focused on explaining variability between children (i.e., interindividual variability) $(9,12,21)$, but PA also shows considerable day-to-day variation within children (i.e., intraindividual variability) (12). As the influence of weather on children's PA patterns is a complex interplay between inter- and intraindividual relationships (24), understanding these relationships requires both knowledge from intraindividual, as well as interindividual mechanisms. Finally, it is also of interest to see whether different effects may occur in population subgroups. For example, overweight or obese children may experience physical complaints or insecurity as a more proximal barrier to perform PA (irrespective of more distal weather elements) (8).

The present study first aims to examine intraindividual associations between daily weather elements and children's PA across a 1-yr time span that reflects variability of weather across four seasons. Our second aim was to examine whether the influence of weather elements differs by day of the week (weekdays vs weekends), gender, age, and body mass index (BMI).

\section{METHODS}

\section{Procedures and Participants}

Primary schools located within a $40-\mathrm{km}$ radius of the Melbourne Central Business District, Australia, and with enrolments of greater than 200 pupils were identified and stratified into tertiles of socioeconomic status (SES) based on postcode using the Socio-Economic Index for Areas (2). In 2012, schools were randomly selected from each SES strata and invited to participate in the Patterns of Habitual
Activity across Seasons study, which used a repeatedmeasures design to examine seasonal changes in children's activity levels (26). Nine schools (one low, three medium, and five high SES) agreed to participate in the study, and the school principal provided written informed consent. Ethical approval for the study was provided by Deakin University Human Ethics Advisory Group Committee, the Department of Education and Early Childhood Development, and the Catholic Education Office (Melbourne).

All children in years 4 and 5 (ages 8-11 yr) were invited to participate in the study $(n=1270)$. Parental written informed consent was provided for 326 children (162 boys and 164 girls; $25.7 \%$ response rate) to participate in at least one component of the study at baseline (i.e., accelerometers, inclinometers, survey, anthropometry, and focus groups). No information was obtained about nonresponders as it is an ethical requirement in Australia for active informed consent to be provided. Data were collected from children during four school terms that closely correspond with each season in southeast Australia: winter (August-September 2012; term 3), spring (October-November 2012; term 4), summer (February-March 2013; term 1), and autumn (May-June 2013; term 2). No data were collected during school holidays.

\section{Measures}

PA. Children's PA was objectively assessed for seven consecutive days in each school term using hip-mounted ActiGraph GT3X+ accelerometers (Pensacola, FL). Raw triaxial data were sampled at $30 \mathrm{~Hz}$ and downloaded and processed into 15-s epochs using ActiLife software (v6). Non-wear time was defined as sustained 20-min periods of consecutive zero counts (4). The intensity of PA was classified using the following age-specific cut points agreeing with METs (10): 1.5-3.99 for light PA (LPA), 4-5.99 for moderate PA (MPA), and $\geq 6$ for vigorous PA (VPA). These cut points have been found to exhibit excellent classification accuracy and are commonly used (30). A valid day was defined as $\geq 8 \mathrm{~h}$ on weekdays and $\geq 7 \mathrm{~h}$ on weekend days. The lower weekend wear time requirement was due to children typically waking later on weekend days (26). For this study, all valid days collected from each school term were included in the analyses.

Anthropometry. Body mass was measured to the nearest $0.1 \mathrm{~kg}$ using a calibrated electronic scale (Tanita BC-351; Tanita, Japan). Stature was measured to the nearest $0.1 \mathrm{~cm}$ using SECA portable stadiometers (model 217; SECA, Germany). Two measurements of body mass and stature were taken and averaged before calculating BMI (weight per square stature, $\mathrm{kg} \cdot \mathrm{m}^{-2}$ ). In the event of a discrepancy of more than $0.1 \mathrm{~kg}$ or $1 \mathrm{~cm}$, a third measurement was taken. All measurements were taken by trained research staff using standardized procedures.

Meteorological data. Meteorological data were obtained for each day of data collection from the publicly accessible Australian Government's Bureau of Meteorology (3). The 
nearest weather station to each participating school was identified, and data were matched to accelerometer wear days in each school. The data obtained were temperature (daily maximum in degrees Celsius), relative humidity (daily average in percentage), solar radiation (daily total in megajoules per square meter), day length (total minutes of daylight per day), and rainfall (daily total in $\mathrm{mm}$ ). Owing to its highly skewed distribution, rainfall was collapsed into three categories: no rainfall (52.5\% of days) and rainfall split into categories of similar size: $0.1-7.8 \mathrm{~mm}$ (23.6\% of days) and $7.9-46.0 \mathrm{~mm} \cdot \mathrm{d}^{-1}$ ( $23.9 \%$ of days). All other weather variables were treated as continuous variables in subsequent models.

\section{Statistical Analyses}

Days were used as the unit of analysis because this allows day-to-day variation within children. Our primary outcome variables were (continuous) daily total minutes classified as MPA and VPA. Temperature, relative humidity, rainfall, solar radiation, and day length were the primary (fixed) explanatory variables. Analyses were generally adjusted for accelerometer daily wear time, school term, gender, age, and BMI.

Our primary aim was to analyze day-to-day PA variation within individual children (intraindividual variation). Therefore, we adjusted for differences between individual children in our model (such as variation related to differences between schools) by allowing multilevel linear mixed models to compute a random intercept for each child and a repeated term for each child across each day of measurement. Theoretically, as a result of investigating day-to-day variation within children using the model specified, additional adjustment for betweensubject variables (such as school or gender) would not improve the model, nor the estimation of our relationship of interest. We found homogenous variances but decreasing covariances with increasing distance between repeated measurements; therefore, we accounted for the covariance between repeated measures by specifying an autoregressive (AR1) covariance structure. Linearity was evaluated for each association, and in the case of curvilinear relationships, quadratic terms were fitted (21).

Multicollinearity was investigated using linear regression analyses. With variance inflation factors (VIF) ranging between 3.9 and 4.4, day length and temperature revealed highest multicollinearity statistics, followed by solar radiation (VIF 3.0). Only removing day length from the model led to notable reduction in multicollinearity statistics (VIF 2.8 and 2.3 for solar and temperature, respectively). We decided to retain all variables in subsequent analyses, as all VIF values were under 4.4 (20).

Potential moderation of gender, age, and BMI, as well as mutual moderation between weather variables (e.g., temperature and relative humidity), was evaluated by systematically investigating interactions and changes in model fit. BMI was dropped from the models investigating MPA as its initial main effect was not statistically significant. Advancing from the multicollinearity statistics computed earlier, we compared results from models with and without day length to investigate whether potential collinearity between temperature and day length would have influenced these interactions. However, as both model variations were highly comparable (data not shown), we retained day length in subsequent interaction models. Finally, we repeated our analyses for LPA and sedentary time. For all analyses, SPSS 21.0 for Windows (IBM SPSS Inc., Armonk, $\mathrm{NY}$ ) was used, and $P<0.05$ indicated statistical significance.

\section{RESULTS}

In total, 307 of 326 children ( $52 \%$ girls) provided valid PA data ( $\geq 1 \mathrm{~d})$ in at least one school term and were included in the analyses. The average age was $11.14 \mathrm{yr}(\mathrm{SD}=0.67$, range $=$ 8.7-12.8) among boys and $11.10 \mathrm{yr}(\mathrm{SD}=0.68)$ among girls. In total, $24.7 \%$ of the boys and $15.9 \%$ of the girls were classified as overweight, and $5.3 \%$ of the boys and $7.6 \%$ of the girls were classified as obese, according to International Obesity Taskforce thresholds for BMI (7).

As we included all valid days in the analyses, participants were allowed to have from 1 to $7 \mathrm{~d}$ of consecutive monitoring per school term. In total, $69 \%$ of participants had valid data for at least $4 \mathrm{~d}$, and $40 \%$ had valid data for $7 \mathrm{~d}$ across the four school terms. Children provided $4597 \mathrm{~d}$ of PA measurement in total, with $31.8 \%$ in winter, $27.9 \%$ in spring, $21.2 \%$ in summer, and $19.1 \%$ in autumn. In total, 156 children (50.8\%) provided data at all four school terms, $81(26.4 \%)$ in three school terms, $54(17.6 \%)$ in two school terms, and $16(5.2 \%)$ in one school term.

PA and weather elements across the school terms are presented in Table 1. In winter and spring terms, children engaged in significantly more MPA compared with summer and autumn $(P$ values $<0.01)$. In addition, VPA differed significantly across all terms, except for spring versus autumn. VPA was highest in winter, followed by spring/autumn and summer.

Weather elements and children's PA patterns. In Table 2, relationships between weather elements and PA are presented. Compared with no rainfall, little rainfall $(0.1-7.8 \mathrm{~mm})$ was associated with more MPA and VPA, whereas more rainfall $(7.9-46.0 \mathrm{~mm})$ was not associated with MPA and VPA. Higher humidity was consistently related to lower MPA and VPA, and solar radiation was related to higher MPA and VPA. Day length showed no association with PA. As can be observed in Figure 1, temperature showed a significant curvilinear relationship with MPA and VPA (reflecting the linear and quadratic variables of temperature in Table 2). The temperature levels that corresponded with highest engagement in MPA and VPA were $22^{\circ} \mathrm{C}$ and $20^{\circ} \mathrm{C}$, respectively. When analyses were repeated for sedentary time, general results were equally strong but in opposite direction (see Table, Supplemental Digital Content 1, Relationship between weather elements and sedentary time and LPA, http:// links.lww.com/MSS/A839). When MPA and VPA results were compared with LPA, differences were found regarding temperature (i.e., no decline in LPA observed at temperatures $>25^{\circ} \mathrm{C}$ ), humidity (i.e., no relationship observed), 
TABLE 1. Distribution of PA and weather variables across the school terms.

\begin{tabular}{|c|c|c|c|c|}
\hline Daily Level ( $n=4599 \mathrm{~d}$ of Measurement) & School Term 1 (Summer) & School Term 2 (Autumn) & School Term 3 (Winter) & School Term 4 (Spring) \\
\hline No. children included (\% from total) & $238(77.5 \%)$ & $212(69.1 \%)$ & $269(87.6 \%)$ & $272(88.6 \%)$ \\
\hline Accelerometer wear time (daily minutes), mean (SD) & $780.0(212.3)^{\star}$ & $807.0(224.6)^{a, d}$ & $826.3(214.9)^{a}$ & $814.7(208.8)^{a}$ \\
\hline Sedentary time (daily minutes), mean (SD) & $467.1(174.6)^{b, c}$ & $492.2(191.8)^{a, d}$ & $492.8(181.3)^{a, d}$ & $473.8(176.1)^{C}$ \\
\hline LPA (daily minutes), mean (SD) & $253.2(70.8)^{d}$ & $249.5(71.9)^{c, d}$ & $258.2(66.4)^{b, d}$ & $267.7(73.1)^{\star}$ \\
\hline MPA (daily minutes), mean (SD) & $43.7(21.0)^{c, d}$ & $45.9(22.2)^{c, d}$ & $50.8(20.6)^{a, b}$ & $51.8(22.3)^{a, b}$ \\
\hline VPA (daily minutes), mean (SD) & $16.7(14.4)^{\star}$ & $19.5(15.2)^{\star}$ & $25.1(18.4)^{\star}$ & $21.4(16.0)^{\star}$ \\
\hline MPA (daily average in \%), mean (SD) & $5.8(2.8)^{c, d}$ & $5.9(2.9)^{c, d}$ & $6.4(2.6)^{a, b}$ & $6.5(2.8)^{a, b}$ \\
\hline VPA (daily average in \%), mean (SD) & $2.2(1.9)^{*}$ & $2.5(2.1)^{a, c}$ & $3.2(2.5)^{\star}$ & $2.7(2.0)^{a, c}$ \\
\hline Rainfall (no. days) $(\%)$ & * & * & * & * \\
\hline No rainfall & $591(60.5)$ & $446(50.8)$ & $532(36.4)$ & $846(66.0)$ \\
\hline $0.01-7.8 \mathrm{~mm} \cdot \mathrm{d}^{-1}$ & $218(22.3)$ & $217(24.7)$ & $514(35.2)$ & $136(10.6)$ \\
\hline $7.9-46.0 \mathrm{~mm} \cdot \mathrm{d}^{-1}$ & $168(17.2)$ & $215(24.5)$ & $416(28.5)$ & $300(23.4)$ \\
\hline Humidity (daily average in percentage), mean (SD) & $60.0(12.6)^{b, c}$ & $71.2(13.0)^{*}$ & $67.2(10.6)^{\star}$ & $61.0(12.3)^{b, c}$ \\
\hline Day length (total daily minutes), mean (SD) & $761.8(34.2)^{*}$ & $599(20.3)^{*}$ & $651.3(21.7)^{*}$ & $851.4(18.7)^{\star}$ \\
\hline Temperature (daily maximum in ${ }^{\circ} \mathrm{C}$ ), mean (SD) & $27.5(5.2)^{*}$ & $16.6(2.8)^{\star}$ & $15.2(2.9)^{\star}$ & $22.6(5.3)^{\star}$ \\
\hline Solar radiation exposure (daily total in $\mathrm{MJ} \cdot \mathrm{m}^{-2}$ ), mean (SD) & $19.56(7.23)^{\star}$ & $6.99(2.61)^{*}$ & $10.28(3.61)^{*}$ & $21.74(7.59)^{*}$ \\
\hline
\end{tabular}

Differences between school terms for continuous variables were tested using Bonferroni-corrected analyses of variance and for categorical variables using chi-square tests.

${ }^{*}$ Statistically significant difference between term in column and all other school terms.

${ }^{a}$ Statistically significant difference between term in column and school term 1 (summer).

${ }^{b}$ Statistically significant difference between term in column and school term 2 (autumn).

${ }^{c}$ Statistically significant difference between term in column and school term 3 (winter).

${ }^{d}$ Statistically significant difference between term in column and school term 4 (spring).

and rainfall (i.e., 7.6-46.0 $\mathrm{mm}$ rainfall associated with more LPA) (see Table, Supplemental Digital Content 1, http://links. lww.com/MSS/A839).

Moderation across weather elements and between sociodemographics and day type. There was statistically significant moderation for solar radiation in the relationship between temperature and MPA and VPA (improvement of the model by including interaction terms $P<0.01$ for both MPA and VPA, likelihood ratio test with $2 d f$ ). This means that the previously computed temperature that corresponded to highest PA depends on the level of solar radiation. We dichotomized solar radiation to graphically demonstrate this. It should be noted that during days with low solar radiation, maximum temperatures only reached $29.1^{\circ} \mathrm{C}$, whereas in days with high solar radiation, temperatures were recorded up to $39.1^{\circ} \mathrm{C}$ (see Figures, Supplemental Digital Content 2, http://links.lww.com/ MSS/A840, and Supplemental Digital Content 3, http://links. lww.com/MSS/A841, Moderation of solar in the relationship between PA and temperature). Consequently, temperature had a smaller influence on children's MPA and VPA during days with lower solar radiation, whereas temperatures $\left(>25^{\circ} \mathrm{C}\right)$ were strongly associated with lower MPA levels during days with high solar radiation (see Figures, Supplemental Digital Content 2, http://links.lww.com/MSS/A840 and Supplemental
Digital Content 3, http://links.lww.com/MSS/A841). This can also be deducted from the negative interaction term solartemperature, whereas the interaction term of the quadratic term solar-temperature squared was positive (see Table, Supplemental Digital Content 4, Moderation of weather elements in relationship between weather elements and PA, http://links. lww.com/MSS/A842).

In addition to the interaction described previously, moderation was also found between day type and temperature in the relationship with VPA (see Table, Supplemental Digital Content 5, Moderation of weather elements and day type in relationship between weather elements and VPA, http:// links.lww.com/MSS/A843). We found a strong curvilinear relationship between temperature and VPA during weekdays, whereas during weekends, temperature was linearly related with lower VPA (see Figure, Supplemental Digital Content 6, Moderation of day type in the relationship between temperature and VPA, http://links.lww.com/MSS/A844). We found no indication for moderation by gender, age, and BMI.

\section{DISCUSSION}

This study first investigated associations between weather elements and children's daily PA patterns and, second, the

TABLE 2. Relationship between weather elements and PA ( $n=4599 \mathrm{~d}, n=307$ children)

\begin{tabular}{|c|c|c|}
\hline & MPA Std. B (95\%Cl) & VPA Std. B (95\% Cl) \\
\hline & -2 restricted log likelihood $=10,834$ & -2 restricted log likelihood $=10,759$ \\
\hline Rainfall $\left(0.01-7.8 \mathrm{~mm} \cdot \mathrm{d}^{-1}\right.$ vs no rainfall) & $0.087(0.029$ to 0.145$)$ & $0.062(0.005$ to 0.119$)$ \\
\hline Rainfall (7.9-46.0 $\mathrm{mm} \cdot \mathrm{d}^{-1}$ vs no rainfall) & $-0.065(-0.152$ to 0.022$)$ & $-0.007(-0.093$ to 0.078$)$ \\
\hline Humidity & $-0.070(-0.108$ to 0.033$)$ & $-0.085(-0.122$ to -0.048$)$ \\
\hline Day length & $-0.050(-0.177$ to 0.076$)$ & $-0.079(-0.202$ to 0.044$)$ \\
\hline Temperature & 0.378 (0.177 to 0.579$)$ & $0.108(-0.089$ to 0.304$)$ \\
\hline Temperature squared & $-0.484(-0.665$ to -0.302$)$ & $-0.297(-0.474$ to -0.120$)$ \\
\hline Solar radiation exposure & $0.079(0.037$ to 0.121$)$ & $0.065(0.024$ to 0.106$)$ \\
\hline Day type (weekday vs weekend day) & 0.438 (0.380 to 0.496$)$ & 0.333 (0.276 to 0.389$)$ \\
\hline Gender (boys vs girls) & 0.523 (0.410 to 0.636$)$ & 0.531 (0.397 to 0.665$)$ \\
\hline Age $(y r)$ & $-0.118(-0.178$ to -0.058$)$ & $-0.051(-0.122$ to 0.019$)$ \\
\hline $\mathrm{BMI}$ & $0.026(-0.026$ to 0.079$)$ & $-0.107(-0.168$ to -0.046$)$ \\
\hline
\end{tabular}

Table shows fixed effects (as standardized regression coefficients [std. B] with 95\% confidence intervals [CI]) from linear mixed models, with a random intercept for each child, and a repeated term for each child across each repeated observation, with autoregressive covariance structure. Bolded data indicate significant at $P<0.05$. 


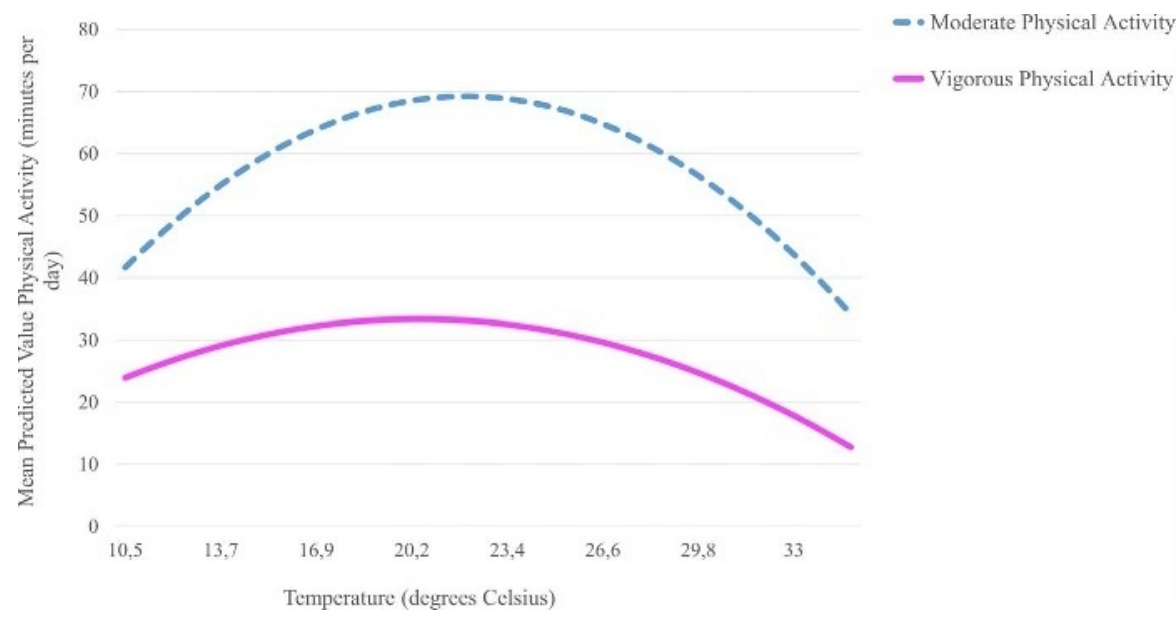

FIGURE 1-Relationship between temperature and PA. Mean unstandardized predicted values of MPA and VPA were adjusted for rainfall, humidity, day length, day type, gender, age, and BMI. For MPA, $P$ value temperature $<0.01 ; P$ value temperature $2<0.01$. For VPA, $P$ value temperature $<$ $0.86 ; P$ value temperature ${ }^{2}<0.01$.

moderating effects of day of the week (weekdays vs weekend days) and gender, age, and BMI on the relationship between these weather elements and PA, using an extensive longitudinal design containing measurements across four seasons. Temperature and day type (weekdays vs weekends) were the strongest variables explaining MPA and VPA, followed by equal contributions from solar radiation and humidity. Temperature showed a curvilinear relationship, with highest engagement in MPA and VPA levels occurring at $22^{\circ} \mathrm{C}$ and $20^{\circ} \mathrm{C}$, respectively. Relative humidity was consistently related to lower MPA and VPA, and solar radiation was consistently related to higher MPA and VPA. Little rainfall $(0.1-7.8 \mathrm{~mm})$ was associated with higher MPA compared with no rainfall, but no association was found for heavier rainfall (7.9-46.0 mm). When compared against sedentary time, results were equally strong but in opposite direction, suggesting that the increments observed in MPA and VPA were accompanied with a similar decrease in sedentary time.

The curvilinear relationship found between temperature and MPA and VPA was highly comparable with results from the study by Lewis et al. (21), which also reported an optimal temperature around $20^{\circ} \mathrm{C}-25^{\circ} \mathrm{C}$ related to PA among children in Australia and Canada. For LPA however, we did not observe this typical curvilinear relationship. In addition, our study found that there was a notable curvilinear relationship between temperature and VPA during weekdays. During weekends, we found no evidence for such a curvilinear relationship, but still, higher temperatures were related to lower VPA. Lewis et al. (21) reported that the influence of weather was stronger on weekdays, whereas Duncan et al. (9) and Atkin et al. (1) in contrast reported that this was generally true for weekend days. Inconsistency regarding these findings may be explained by the possibility that on weekends with temperatures higher than $20^{\circ} \mathrm{C}$, more free time may have been spent in water-related activities, which likely resulted in misclassification of actual PA behavior as children were instructed to not wear the accelerometer during water activities (21). Another explanation may be that the scheduling of structured PA (e.g., team sports) may have resulted in fewer PA opportunities in warmer periods of the year (26). However, by allowing for an individualized intercept and repeated measures for each participant across each day of measurement, it is more conceivable that daily changes in temperature influenced PA in our study rather than the role of potential changes in structured PA.

We found that solar radiation was consistently associated with higher MPA and VPA. Duncan et al. (9) also examined solar exposure in their New Zealand study, but no associations were found with PA (9). This may be due to different definitions of solar radiation, as the present study defined solar radiation as the daily total in megajoules per square meter, whereas Duncan et al. (9) defined solar radiation as the duration of absent cloud cover. As the former provides more valid information about the actual intensity of solar radiation, this measure may be more likely to be related with PA behavior. In addition, although suggested by Duncan et al. (9), this is the first study that has investigated moderation mechanisms between weather elements and their association with PA. Such moderation was found for temperature and solar radiation. Apart from the potential influence of water-related activities, sun protection policies may also have influenced children's PA particularly during the warmer months. At higher intensities of solar radiation (UV levels $\geq 3$ ), SunSmart protection measures in Australia encourage children to stay in the shade and wear protective clothing (e.g., hats and long sleeve tops) during periods of the day with extreme UV levels. This may have hindered children's participation in outdoor PA (18) and, thus, may have contributed to the moderation between temperature and day type in the relationship with VPA (see Figure, Supplemental Digital Content 6, http:// links.lww.com/MSS/A844). Similar school policies regarding promotion of indoor PA during wet weather conditions (14) may also be required during periods of the day with extreme UV levels. 
Although we found consistent associations between relative humidity and lower PA, Lewis et al. (21) found no such associations with MVPA (21). Humidity may influence PA in a way that the sensation of heat (at higher temperatures) depends on relative humidity $(27,28)$, which suggests a moderating mechanism between temperature and humidity in the relationship with PA. However, no evidence for interaction was found in our study. Therefore, regardless of temperature, PA may be more exhausting and uncomfortable for children in higher relative humidity, and therefore it may be best to encourage indoor activities on days of high humidity. Moreover, no associations were found between humidity and LPA. Similar to temperatures higher than $25^{\circ} \mathrm{C}$, increments in humidity are especially related to declines in PA at high intensity. This may mean that these meteorological circumstances may discourage and/or limit children from performing MPA/VPA because of discomfort and/or increased fatigue.

Except for positive associations in the Canadian sample examined by Lewis et al. (21), five studies reported negative associations between rainfall and PA $(9,12,21)$. In the current study, however, results regarding rainfall were mixed. Interestingly, only Duncan et al. (9) and Harrison et al. $(14,15)$ categorized of rainfall because of its skewed distribution (9). Unlike the study of Duncan et al. (9) but in line with the studies of Harrison et al. $(14,15)$, the categorization of rainfall in our study was based on days with no rainfall and subsequently split into two categories of similar size. When we applied the same category thresholds as Duncan et al. (9), however, results remained unchanged. A potential explanation for the mixed rainfall findings in our study may be that children performed PA between rain showers, or inside during rainfall. As we had no data on the rainfall characteristics (e.g., intensity, duration, or timing of rainfall) or indoor/ outdoor timing, we cannot speculate how much influence rainfall had on children's daily PA levels. In addition, future studies that have access to wind speed data may also investigate whether average daily wind speed (or in a moderation mechanism with rainfall) influence children's PA behavior. Interestingly, one study reported clear declines in lunchtime and after-school PA with increasing rainfall in 9- to 11-yr-old children, but no associations were found for 13- to 14-yr-old children (15). Unfortunately, our daily rainfall data and limited age range do not allow direct comparison with these findings (15). Future studies are encouraged to include rainfall characteristics and indoor/outdoor time in their analyses, as preliminary results indicated that children were most active in schools with policies to provide opportunities for active indoor activities during wet weather (14).

Given our longitudinal design across four school terms, substantial variations in day length were recorded in our study; however, no associations between day length and PA were observed. Unlike the study of Goodman et al. (12), we entered day length as a continuous variable in our models. When we computed tertiles based on equal frequency distributions; however, some small differences in MPA were found but results were inconsistent (data not shown). Initial multicollinearity statistics provided indications for potential multicollinearity between day length, temperature, and solar radiation. Hence, we investigated this in sensitivity analyses. For example, removing temperature or solar radiation from our models led to significant decrease in model fit $(P<0.05$ for MPA and VPA), whereas the association between day length and MPA remained unchanged (data not shown). On the basis of these sensitivity analyses, we decided to retain day length in the models as we deemed multicollinearity not to have significantly influenced our results. However, in line with the present study, previous studies reported that associations between day length and PA were only strong during the late afternoon and early evening (12), and only small increases in overall daily PA were shown between days with large differences in sunset times (i.e., before 5:00 p.m. vs after 9:00 p.m.) (11). Consequently, day length may independently increase PA in late afternoons and evenings, but associations between day length and overall PA across the whole day seem to be weak (11).

According to the results of Goodman et al. (12), this may be due to an increase in LPA during late afternoon or early evenings. In addition, it is possible that day length might have less influence on PA performed as part of organized sports versus discretionary PA (e.g., sports facilities may be more likely to be lit than playgrounds). Future studies are encouraged to further examine these distinct PA patterns.

Strengths and weaknesses. To our knowledge, this is the first study to use a longitudinal design to investigate the influence of weather elements on children's intraindividual PA patterns. The repeated measurements distributed across four school terms within $1 \mathrm{yr}$ ensured variation in weather elements and are representative of yearly PA patterns among Australian children.

The present study's approach of PA patterns within individuals is different from earlier studies. These studies typically analyzed between-individual differences, aggregating PA for days. Within-individual analyses, such as in our study, are better able to characterize day-to-day variation in children, helping us to understand PA patterns in children.

In our study, the lowest average temperature recorded was $10.7^{\circ} \mathrm{C}$. Therefore, these findings may not be generalized to countries with lower winter temperatures. In addition, weather elements also show within-day variability (e.g., short periods of heavy rainfall may have a different influence on PA than prolonged light rainfall) (12). Future studies are encouraged to also analyze within-day variability of weather elements in relation to PA patterns, particularly in regions where the weather is highly variable across the day. Although we accounted for differences between each day of measurement within children (as a repeated term) and thus also for potential differences in sports participation across school terms, the influence of weather elements may still be underestimated by indoor sports participation. Related to this, future studies may also investigate whether the relationship between weather 
elements and PA is consistent over time. Underestimation of our results may also stem from children's cycling behavior, which is not well captured by hip-worn accelerometers, but may vary according to weather elements (23). One could also argue that despite this study controlling for wear time, our results may be influenced by differences in wear time across school terms. For example, especially in summer, wear time (and VPA) was lower compared with other school terms. However, sensitivity analyses revealed that no notable changes were detected when models were repeated for low versus high wear time (data not shown). Finally, we were unable to account for the possibility that water-based PA may have influenced our results in warmer periods of the year. The use of extensive PA diaries or combined global positioning system and accelerometer methodology in future studies may be able to recognize specific types of PA and their context.

Implications. This study has important implications for future study methodology. As weather influences cannot be controlled, knowledge of its influence on individual PA patterns may inform the design, analysis, and interpretation of future studies, especially when investigating PA across diverse meteorological settings and with long follow-up periods. Also, future interventions should not only account for interindividual but also for intraindividual changes of

\section{REFERENCES}

1. Atkin AJ, Sharp SJ, Harrison F, Brage S, van Sluijs EM. Seasonal variation in children's physical activity and sedentary time. Med Sci Sports Exerc. 2016;48(3):449-56.

2. Australian Bureau of Statistics Website [Internet]. Census of Population and Housing: Socio-Economic Indexes for Areas (SEIFA), Australia; [cited 2012 May 1]. Available from: http://www.abs.gov. au/ausstats/abs@.nsf/mf/2033.0.55.001.

3. Australian Government's Bureau of Meteorology Website [Internet]. Australian Government's Bureau of Meteorology; [cited 2015 Nov 20]. Available from: http://www.bom.gov.au/.

4. Cain KL, Sallis JF, Conway TL, Van Dyck D, Calhoon L. Using accelerometers in youth physical activity studies: a review of methods. J Phys Act Health. 2013;10(3):437-50.

5. Carson V, Spence JC. Seasonal variation in physical activity among children and adolescents: a review. Pediatr Exerc Sci. 2010;22(1):81.

6. Chan CB, Ryan DA. Assessing the effects of weather conditions on physical activity participation using objective measures. Int $J$ Environ Res Public Health. 2009;6(10):2639-54.

7. Cole TJ, Bellizzi MC, Flegal KM, Dietz WH. Establishing a standard definition for child overweight and obesity worldwide: international survey. BMJ. 2000;320(7244):1240.

8. Deforche BI, De Bourdeaudhuij IM, Tanghe AP. Attitude toward physical activity in normal-weight, overweight and obese adolescents. J Adolesc Health. 2006;38(5):560-8.

9. Duncan JS, Hopkins WG, Schofield G, Duncan EK. Effects of weather on pedometer-determined physical activity in children. Med Sci Sports Exerc. 2008;40(8):1432-8.

10. Freedson P, Pober D, Janz KF. Calibration of accelerometer output for children. Med Sci Sports Exerc. 2005;37(11 Suppl):S523-30.

11. Goodman A, Page AS, Cooper AR, International Children's Accelerometry Database (ICAD) Collaborators. Daylight saving time as a potential public health intervention: an observational study of evening daylight and objectively-measured physical activity among 23,000 children from 9 countries. Int J Behav Nutr Phys Act. 2014;11(1):84. weather elements in their analyses. This study also has implications for countries that often experience high temperatures $\left(>25^{\circ} \mathrm{C}\right)$. As this study showed substantially lower levels of PA at these high temperatures, researchers are encouraged to investigate mechanisms behind this inactivity (e.g., parents/ schools keeping children inside or children's own inclination to be less active). Policy makers in these countries are advised to provide infrastructure to promote and support appropriate PA in these temperatures while being cautious about adverse health effects of high solar radiation and overheating.

The authors gratefully acknowledge the contribution of all participating children and project staff. They also acknowledge Eoin O'Connell for the development of the customized Excel macro. T. R. was supported by the University Fund Limburg (grant no. 15.021). The Patterns of Habitual Activity across Seasons Study and N. D. R. were supported by an Australian Research Council Discovery Early Career Researcher Award (grant no. DE120101173). J. S. was supported by a National Health and Medical Research Council Principal Research Fellowship (grant no. APP1026216). A. T. was supported by a Future Leader Fellowship from the National Heart Foundation of Australia (award ID 100046). J. V. was supported by a National Health and Medical Research Council Early Career Fellowship (ID 1053426). The authors declare that they have no competing interests. Study results and methodology are presented clearly, honestly, and without fabrication, falsification, or inappropriate data manipulation. Results of the present study do not constitute endorsement by the American College of Sports Medicine.

12. Goodman A, Paskins J, Mackett R. Day length and weather effects on children's physical activity and participation in play, sports, and active travel. J Phys Act Health. 2012;9(8):1105.

13. Hallal PC, Andersen LB, Bull FC, Guthold R, Haskell W, Ekelund U. Global physical activity levels: surveillance progress, pitfalls, and prospects. Lancet. 2012;380(9838):247-57.

14. Harrison F, Jones AP, Bentham G, van Sluijs EM, Cassidy A, Griffin SJ. The impact of rainfall and school break time policies on physical activity in 9-10 year old British children: a repeated measures study. Int J Behav Nutr Phys Act. 2011;8:47.

15. Harrison F, Van Sluijs EM, Corder K, Ekelund U, Jones A. The changing relationship between rainfall and children's physical activity in spring and summer: a longitudinal study. Int J Behav Nutr Phys Act. 2015;12:41.

16. Janssen I, LeBlanc AG. Systematic review of the health benefits of physical activity and fitness in school-aged children and youth. Int J Behav Nutr Phys Act. 2010;7(40):1-16.

17. Jones RA, Hinkley T, Okely AD, Salmon J. Tracking physical activity and sedentary behavior in childhood: a systematic review. Am J Prev Med. 2013;44(6):651-8

18. Jones SB, Beckmann K, Rayner J. Australian primary schools' sun protection policy and practice: evaluating the impact of the National SunSmart Schools Program. Health Promot J Austr. 2008;19(2): 86-90.

19. Kolle E, Steene-Johannessen J, Andersen LB, Anderssen SA. Seasonal variation in objectively assessed physical activity among children and adolescents in Norway: a cross-sectional study. Int $J$ Behav Nutr Phys Act. 2009;6:36.

20. Kutner MH, Nachtsheim C, Neter J. Applied Linear Regression Models. 4th ed. Boston (MA): McGraw-Hill Education; 2004. p. 387

21. Lewis L, Maher C, Belanger K, Tremblay M, Chaput J, Olds T. At the mercy of the gods: associations between weather, physical activity and sedentary time in children. Pediatr Exerc Sci. 2016; 28(1):152-63. 
22. Martin S, Carlson S. Barriers to children walking to or from school. Morb Mortal Wkly Rep. 2005;54(38):949-52.

23. Martin SL, Lee SM, Lowry R. National prevalence and correlates of walking and bicycling to school. Am J Prev Med. 2007;33(2):98-105.

24. Mattocks C, Leary S, Ness A, et al. Intraindividual variation of objectively measured physical activity in children. Med Sci Sports Exerc. 2007;39(4):622-9.

25. Rich C, Griffiths LJ, Dezateux C. Seasonal variation in accelerometerdetermined sedentary behaviour and physical activity in children: a review. Int J Behav Nutr Phys Act. 2012;9:49.

26. Ridgers ND, Salmon J, Timperio A. Too hot to move? Objectively assessed seasonal changes in Australian children's physical activity. Int J Behav Nutr Phys Act. 2015;12:77.
27. Rothfusz LP. The Heat Index Equation (or, More Than You Ever Wanted to Know about Heat Index). Fort Worth (TX): National Oceanic and Atmospheric Administration, National Weather Service, Office of Meteorology; 1990. pp. 90-23.

28. Steadman RG. The assessment of sultriness. Part I: a temperaturehumidity index based on human physiology and clothing science. J Appl Meteorol. 1979;18(7):861-73.

29. Strong WB, Malina RM, Blimkie CJ, et al. Evidence based physical activity for school-age youth. J Pediatr. 2005;146(6): $732-7$.

30. Trost SG, Loprinzi PD, Moore R, Pfeiffer KA. Comparison of accelerometer cut points for predicting activity intensity in youth. Med Sci Sports Exerc. 2011;43(7):1360-8. 